\title{
Effect of extraction techniques on anthocyanin from butterfly pea flowers (Clitoria ternatea L.) cultivated in Vietnam
}

\author{
Nguyen Minh Thuy ${ }^{1 *}$ (D), Tran Chi Ben ${ }^{1}$, Vo Quang Minh ${ }^{2}$ (D), Ngo Van Tai ${ }^{1}$ (D) \\ ${ }^{1}$ College of Agriculture, Can Tho University, Can Tho, Vietnam. \\ ${ }^{2}$ College of Environment and Natural Resources, Can Tho University, Can Tho, Vietnam.
}

\begin{tabular}{l}
\hline ARTICLE INFO \\
\hline Article history: \\
Received on: June 07, 2021 \\
Accepted on: August 28, 2021 \\
Available online: November 10, 2021 \\
\hline
\end{tabular}

Key words:

Total anthocyanin, butterfly pea flowers, extraction techniques, FRAP, multiple regression analysis

\begin{abstract}
The butterfly pea flower (Clitoria ternatea) has attracted much interest recently due to its potential application as a source of natural food colorings and antioxidants. Along with conventional methods, this study applied ultrasound and microwave techniques in the extraction of natural pigments, as well as bioactive compounds. For this purpose, ultrasound-assisted extraction (UAE) (temperature $60^{\circ} \mathrm{C}-80^{\circ} \mathrm{C}$, time $15-60$ minutes, solid-toliquid ratio 5:100 $(\mathrm{g} / \mathrm{ml}), 490 \mathrm{~W}$, and $42 \mathrm{kHz}$ frequency), microwave-assisted extraction (MAE) (microwave's power levels $200-600 \mathrm{~W}$, time 3-6 minutes), and conventional extraction $(\mathrm{CE})$ (temperature $60^{\circ} \mathrm{C}-80^{\circ} \mathrm{C}$, time 15-60 minutes) were applied. The results showed a significant $(p<0.05)$ effect of MAE and UAE on anthocyanins and antioxidant activities ferric reducing antioxidant power (FRAP) of butterfly pea flowers extract in comparison with CE. The MAE and UAE methods improved anthocyanin yield by $14.11 \%$ and $15.01 \%$ with the highest total anthocyanin content obtained by UAE $\left(70^{\circ} \mathrm{C}\right.$ and 5 minutes $)$. Multiple regression analysis was performed to select the optimal parameters by UAE $\left(74^{\circ} \mathrm{C}\right.$ for 56.88 minutes) with the highest concentration of anthocyanins $(39.90 \mathrm{mg} / \mathrm{l})$ and FRAP $\left(\mu \mathrm{MFeSO}_{4} / 100 \mathrm{ml}\right)$ in the extract. Five anthocyanin compounds, delphinidin-hex, cyanidin-hexose-deoxyHex, delphinidin-deoxyhex-hex, cyanidin-hexose-2 deoxyHex, and delphinidin-hexose-2 deoxyHex, were identified in the extract.
\end{abstract}

\section{INTRODUCTION}

The butterfly pea (Clitoria ternatea L.), commonly known as the blue pea, is a plant species from the family Fabaceae. It has recently been of interest because of its potential for medical applications and as a source of natural food colorings and antioxidants that can be added to foods to increase the attractiveness of food products. This flower is one of the most interesting sources of polyacylated anthocyanins because it provides blue color in neutral and low acidic solutions $[1,2]$. However, the very short shelf life limits the commercial use of these flowers. The butterfly pea flower is a natural source of antioxidants with high concentrations of phenolic compounds, flavonoids, and anthocyanins in the extract [3], which play an important role in human health [4].

\footnotetext{
*Corresponding Author

Nguyen Minh Thuy, College of Agriculture, Can Tho University, Can Tho, Vietnam.E-mail:nmthuy@ctu.edu.vn
}

Extraction procedures include Soxhlet extraction and ultrasonicand microwave-assisted extraction (MAE) [5]. MAE is one of the advanced extraction processes in the preparation of medicinal plants. This method is suitable for the extraction of flavonoids. The main advantage of MAE is its ability to rapidly heat sample solvent mixtures, leading to its wide applicability for the rapid extraction of analytes, including thermally unstable ones $[5,6]$. MAE has special advantages such as minimizing solvents and extraction time as well as increasing yield. The ultrasonic-assisted extraction process involves the use of sound energy at very high frequencies greater than $20 \mathrm{kHz}$ to disrupt all plant cells and increase the drug surface area for the solvent to penetrate [5]. Ultrasonic-assisted extraction can be applied to small samples; extraction time was reduced, low amount of solvent used, and yield maximized [7]. The common solvents used in plant extracts are water, alcohol, acetone, and so forth. The effectiveness of solvents was varied in extracting bioactive compounds from plants, depending on the intended use. In this study, water was used as the solvent for the extraction, and the effectiveness of extraction methods was analyzed and compared. Multiple regression analysis was 
conducted for the most suitable extraction conditions to predict and get the optimal values.

\section{MATERIAL AND METHODS}

\subsection{Preparation of Butterfly Pea Flowers}

Butterfly pea flowers were grown at the College of Agriculture, Can Tho University, Vietnam. After harvesting, butterfly pea flowers were washed with running tap water and drained. The sample was arranged on trays (stainless steel) and dried at $70^{\circ} \mathrm{C}$ in a convectional air oven (SIBATA SD60, Japan) with an airflow speed of $1.0 \mathrm{~m} / \mathrm{s}$, parallel to the drying surface of the samples. The dried sample (5\%-6\% moisture) was packed in dark bags and kept at ambient temperature $\left(28^{\circ} \mathrm{C} \pm 2^{\circ} \mathrm{C}\right)$ for further use.

This study was conducted from August 2020 to May 2021 in the Department of Food Technology, Can Tho University, Vietnam.

\subsection{Extraction Procedure}

The ratio of raw materials (butterfly pea flower) to solvent (water) is 1:20 $(w / v)$. The dried material (10 g) was used for each treatment.

\subsubsection{Conventional extraction (CE)}

Extraction was started by mixing $10 \mathrm{~g}$ of dried pea flowers (moisture content of 3\%-5\%) in $200 \mathrm{ml}$ of water, using a $250 \mathrm{ml}$ Erlenmeyer flask with different extraction temperatures (from $60^{\circ} \mathrm{C}$ to $80^{\circ} \mathrm{C}$ ) and times (from 15 to 60 minutes). The samples were then centrifuged for 30 minutes $\left(13,000 \mathrm{~g}, 25^{\circ} \mathrm{C}\right)(\mathrm{Z} 232 \mathrm{~K}$, Hermle, Gosheim, Germany).

\subsubsection{Ultrasound-assisted extraction (UAE)}

UAE was conducted in an ultrasonic bath (490 W, $42 \mathrm{kHz}$, USA). Samples were prepared similarly to the CE (as mentioned above). The process temperature was controlled at $60^{\circ} \mathrm{C}-80^{\circ} \mathrm{C}$. Triplicate experiments were carried out.

\subsubsection{Microwave-assisted extraction (MAE)}

Samples were prepared in the same way as CE (as mentioned above). The extraction process was conducted in a microwave oven (LG MS2595DIS, Korea) with three energy levels (200, 400, and $600 \mathrm{~W}$ ) for 3-6 minutes. Each experiment was performed three times. The extracts were centrifuged (Z232K, Hermle, Germany) for 30 minutes at $13,000 \mathrm{~g}$ at room temperature to obtain the supernatant. The clear liquid was obtained after being passed through the filter paper (Whatman no. 4, UK), which was stored in the refrigerator for further analysis.

\subsection{Chemical Analysis}

\subsubsection{Determination of total anthocyanin content (TAC)}

TAC was analyzed using the differential $\mathrm{pH}$ method described by Guisti and Wrolstad [8]. The pH-difference method is based on the reaction at $\mathrm{pH} 1$ and 4.5, allowing accurate and rapid measurement of total anthocyanins. Briefly, $1 \mathrm{ml}$ of the extract was reacted with potassium chloride buffer $(0.0025 \mathrm{M}, \mathrm{pH} 1.0)$ and sodium acetate buffer (0.4 M, pH 4.5). The mixture was incubated for 15 minutes at ambient temperature. The absorbance of each dilution at 510 and $700 \mathrm{~nm}$ was measured on a blank cuvette filled with distilled water. The calculation of TAC is based on the equation described by Guisti and Wrolstad [8].

\subsubsection{Determination of the ferric reducing antioxidant power (FRAP)}

Antioxidant power was determined using the FRAP assay [9]. $0.1 \mathrm{ml}$ of the butterfly pea flower extract was mixed with FRAP reagent in a volume ratio of 1:20. The mixture was incubated for the reaction in the dark at ambient temperature for 30 minutes. Based on the color products (iron tripyridyltriazine complex), its absorbance was measured at $593 \mathrm{~nm}$ using a UV/Vis spectrophotometer (Shimadzu, Kyoto, Japan). Calibration curves were established and the results expressed in $\mu \mathrm{MFeSO}_{4} / 100 \mathrm{ml}$.

\subsection{Data Analysis}

\subsubsection{Identification of anthocyanin compounds}

Anthocyanins and their derivatives were determined using LCESI-QQQ (6460 Triple Quadrupole System, Agilent, Santa Clara, CA) in combination with a UV detector (1260 Infinity, Agilent, Santa Clara, CA).

\subsubsection{Measured data analysis}

Statistically significant differences in the antioxidant properties of the butterfly pea flower extract were determined using software Statgraphics Centurion XV.I (Statistical Graphics Corp., USA). The multiple regression analysis was conducted with TAC and FRAP as the response. The reference equation was selected to fit the data, based on the $R^{2}$ obtained from the multiple regression analysis. The selected reference equation should have a higher $R^{2}$.

\section{RESULTS AND DISCUSSION}

\subsection{Comparison of Different Extraction Techniques for Butterfly Pea Flowers}

The changes of TAC under different extraction conditions and groups of factors affecting the extraction process are shown in Tables 1 and 2. The extracts were different in anthocyanin content corresponding to different extraction conditions. Currently, many new extraction methods have been introduced, including ultrasonicand MAE $[5,7,10]$. These methods can reduce energy consumption and time and maintain high anthocyanin content in the extracts [11].

\subsubsection{Conventional extraction (CE)}

Anthocyanins were obtained differently when extracted in hot water under different conditions. When increasing the extraction time from 15 to 45 minutes, the obtained TAC gradually increased. However, when increasing the extraction time to 60 minutes, the TAC in the butterfly pea flower extract tended to decrease.

Furthermore, the extraction temperature also affects the TAC in the extract. Usually, by increasing the extraction temperature and time, the mass transfer from the plant material into the extract during extraction was easier due to the diffusion rate and solubility of the compounds that were increased [12]. In addition, under 

2021;9(06):173-180

Table 1. CE, UAE, and microwave-assisted (MAE) extraction techniques for anthocyanin of butterfly pea flowers.

\begin{tabular}{ccccc}
\multicolumn{2}{c}{ Extraction method } & \multicolumn{3}{c}{ Extraction method } \\
Temp. $\left({ }^{(} \mathbf{C}\right)$-time (minute) & CE & UAE & Power (W)-time (minute) & MAE \\
$60-15$ & $28.92^{\mathrm{a}}$ & $32.95^{\mathrm{a}}$ & $200-3$ & $36.24^{\mathrm{c}}$ \\
$60-30$ & $29.95^{\mathrm{b}}$ & $34.05^{\mathrm{c}}$ & $200-4$ & $37.08^{\mathrm{c}}$ \\
$60-45$ & $30.51^{\mathrm{c}}$ & $35.05^{\mathrm{d}}$ & $200-5$ & $37.57^{\mathrm{cd}}$ \\
$60-60$ & $30.22^{\mathrm{bc}}$ & $35.05^{\mathrm{d}}$ & $200-6$ & $38.28^{\mathrm{cd}}$ \\
$70-15$ & $31.05^{\mathrm{d}}$ & $36.51^{\mathrm{f}}$ & $400-3$ & $32.94^{\mathrm{b}}$ \\
$70-30$ & $33.14^{\mathrm{e}}$ & $36.99^{\mathrm{g}}$ & $400-4$ & $36.51^{\mathrm{c}}$ \\
$70-45$ & $34.64^{\mathrm{hi}}$ & $39.84^{\mathrm{j}}$ & $400-5$ & $39.53^{\mathrm{d}}$ \\
$70-60$ & $34.23^{\mathrm{g}}$ & $39.14^{\mathrm{i}}$ & $400-6$ & $39.64^{\mathrm{d}}$ \\
$80-15$ & $28.58^{\mathrm{a}}$ & $33.04^{\mathrm{b}}$ & $600-3$ & $29.39^{\mathrm{a}}$ \\
$80-30$ & $30.14^{\mathrm{bc}}$ & $36.04^{\mathrm{e}}$ & $600-4$ & $31.73^{\mathrm{b}}$ \\
$80-45$ & $35.01^{\mathrm{i}}$ & $39.87^{\mathrm{j}}$ & $600-5$ & $33.68^{\mathrm{b}}$ \\
$80-60$ & $33.67^{\mathrm{f}}$ & $38.24^{\mathrm{h}}$ & $600-6$ & $31.45^{\mathrm{ab}}$ \\
\hline
\end{tabular}

Values with different superscripts (in the column) are significantly different $(p<0.05)$.

Table 2. Mean of anthocyanin in extract by treatment level under different extraction conditions.

\begin{tabular}{|c|c|c|c|c|}
\hline \multicolumn{3}{|c|}{ Extraction method } & \multicolumn{2}{|c|}{ Extraction method } \\
\hline Level of variable & CE & UAE & Power (W)-time (minute) & MAE \\
\hline \multicolumn{3}{|c|}{ Temperature $\left({ }^{\circ} \mathrm{C}\right)$} & \multicolumn{2}{|l|}{ Power $(\mathrm{W})$} \\
\hline 60 & $29.90^{\mathrm{a}}$ & $34.20^{\mathrm{a}}$ & 200 & $37.29^{\mathrm{b}}$ \\
\hline 70 & $33.26^{\mathrm{c}}$ & $38.12^{\mathrm{c}}$ & 400 & $37.18^{\mathrm{b}}$ \\
\hline 80 & $31.85^{\mathrm{b}}$ & $36.80^{\mathrm{b}}$ & 600 & $31.56^{\mathrm{a}}$ \\
\hline \multicolumn{3}{|c|}{ Extraction time (minute) } & \multicolumn{2}{|c|}{ Extraction time (minute) } \\
\hline 15 & $29.52^{\mathrm{a}}$ & $34.17^{\mathrm{a}}$ & 3 & $32.86^{\mathrm{a}}$ \\
\hline 30 & $31.08^{\mathrm{b}}$ & $35.69^{\mathrm{b}}$ & 4 & $35.11^{\mathrm{b}}$ \\
\hline 45 & $33.38^{\mathrm{c}}$ & $38.25^{\mathrm{c}}$ & 5 & $36.93^{\circ}$ \\
\hline 60 & $32.71^{\mathrm{c}}$ & $37.48^{\mathrm{c}}$ & 6 & $36.45^{c}$ \\
\hline
\end{tabular}

Values with different superscripts (within the column) are significantly different $(p<0.05)$.

high temperatures, plant tissues softened and weak interactions affected cell membranes. As a result, the phenolic compounds can be easily extracted into the solvents [13]. However, a prolonged extraction time at $80^{\circ} \mathrm{C}$ reduced the extraction yield because the high temperature induced oxidation and decomposition of the desired compounds [14,15].

The results showed that the obtained anthocyanins gradually increased when the heating temperature was from $60^{\circ} \mathrm{C}$ to $80^{\circ} \mathrm{C}$, but, at the heating temperatures of $70^{\circ} \mathrm{C}$ and $80^{\circ} \mathrm{C}$, the obtained solution did not have a significant difference in anthocyanin content. From the obtained results, it was found that a too short or too long time also could not obtain high TAC. Because of the short-time extraction, anthocyanin might not fully dissolve into the extraction solvent. On the other hand, anthocyanins are not temperature stable, so when extracted for a long time at high temperatures, TAC can be degraded [16].

\subsubsection{Ultrasound-assisted extraction}

Temperature has an effect on anthocyanin extract from butterfly pea flowers. TAC of the butterfly pea flower extract increased when the temperature increased from $60^{\circ} \mathrm{C}$ to $70^{\circ} \mathrm{C}$ (from 34.20 to
$38.12 \mathrm{mg} / \mathrm{l})$ and tended to decrease when the temperature reached $80^{\circ} \mathrm{C}(36.80 \mathrm{mg} / \mathrm{l})$.

Besides avoiding exposure to high temperatures [17], UAE was used to reduce extraction time. The obtained results show that extraction time also affects anthocyanin content of the butterfly pea flower extract; this content increases with increasing time from 15 to 60 minutes, but there is no significant difference in TAC obtained from extract for 45 and 60 minutes.

These results are similar to those of Anthika et al. [18]. The extraction time of the butterfly pea flower was carried out in 45 minutes to obtain the highest anthocyanin content of $42.02 \mathrm{mg} / 1$. Waves could cause tissue rupture for a long time of extraction, the solutes are removed and anthocyanins are produced more and more. This phenomenon occurs because the diffusion of the compound from the raw material into the solvent increases to a certain extent with the extraction time [17].

\subsubsection{Microwave-assisted extraction (MAE)}

After extraction at 3 and 5 minutes, anthocyanin content of the butterfly pea flower extract increased with extraction time 
from 32.86 to $39.60 \mathrm{mg} / 1$, respectively. However, when the extraction time was over 5 minutes, anthocyanin content in the butterfly pea flower extract tended to decrease. This is probably because extraction time affects the dielectric properties of the solvent. Therefore, prolonged exposure to microwaves can cause degradation of target compounds due to substances in the system overheating [19].

A higher temperature helps induce intracellular pressure which ruptures the cell wall and leads to higher anthocyanin solubility as well as reduced viscosity of the extract [20]. Anthocyanin was easily affected by heat. As the temperature increases too high, the anthocyanin content in the extract may decrease. Anthocyanin content of the butterfly pea flower extract decreased from 37.29 to $31.56 \mathrm{mg} / \mathrm{l}$ when the energy levels were set at 200 and $600 \mathrm{~W}$, respectively.

3.1.4. Comparison of selection conditions by different techniques for butterfly pea flowers

The obtained results from our study showed that both the UAE and MAE methods clearly improved the TAC in the extract, with the highest concentration found by UAE (Table 3). At the same temperature and extraction time, anthocyanin content of the butterfly pea flower extract from the UAE and MAE techniques increased to $15.01 \%$ and $14.11 \%$, respectively. UAE can effectively improve the recovery of bioactive compounds, and ultrasonic radiation can disrupt cell walls allowing better penetration of solvents into the material's interior, thereby improving mass transfer and cell disruption [7,21]. MAE is also an efficient extraction technique that converts microwave energy to heat quickly [22], with reduced solvent usage, shorter time, and higher yield recovery [23]. In this study, it was clearly observed that using UAE for extracting the anthocyanin in butterfly pea flowers was more effective than MAE. Ultrasound creates holes, disrupting the cell walls, allowing solvents to transfer mass, thereby increasing extraction efficiency [24,25].

3.2. Multiple regression analysis for antioxidant properties for butterfly pea flower extract by $U A E$

Multiple regression is allowed to determine the overall fit of the model and the relative contribution of each predictor to the total explained variance. Statgraphics Centurion XV.I was used to analyze the actual data (Table 4). The quadratic models for anthocyanin and iron reducing antioxidant power (FRAP) of butterfly pea flower extracts affected by extraction time and temperature using the UAE technique are presented in (1) and (2).

The high values of $R^{2}$ for each response indicated that the multiple regression analysis fitted well into the model that was developed. These results confirmed the predictability of the models in determining the optimum conditions needed to obtain the highest TAC and antioxidant activity of the butterfly pea flowers extract.

$$
\begin{aligned}
& \mathrm{TPC}_{\mathrm{UAE}}=-92.72+3.59 A-0.008 B-0.0258 A^{2}+0.004 A B- \\
& 0.0026 B^{2}
\end{aligned}
$$

\begin{tabular}{|c|c|c|c|}
\hline \multirow{2}{*}{ Bioactive compounds } & \multicolumn{3}{|c|}{ Extraction methods and conditions } \\
\hline & $\mathrm{CE}\left(\mathbf{7 0}^{\circ} \mathrm{C}-45\right.$ minutes $)$ & UAE $\left(70^{\circ} \mathrm{C}-45\right.$ minutes $)$ & MAE (400 W-5 minutes) \\
\hline TAC (mg/l) & 34.98 & $39.89\left(+15.01 \%{ }^{\mathrm{a}}\right)$ & $39.34\left(+14.11 \%{ }^{b}\right)$ \\
\hline
\end{tabular}

Table 3. Comparison of anthocyanin contents of extract from different extraction methods.

Table 4. The change of antioxidant properties under different extraction conditions by the UAE technique.

\begin{tabular}{llll} 
Temperature $\left({ }^{\circ} \mathbf{C}\right)$ & Extraction time (minute) & TAC $(\mathbf{m g} / \mathbf{l})$ & FRAP $\left(\mu \mathrm{MFeSO}_{4} / \mathbf{1 0 0} \mathbf{~ m l}\right)$ \\
60 & 15 & $32.95 \pm 0.004$ & $120.72 \pm 1.294$ \\
60 & 30 & $34.05 \pm 0.003$ & $124.97 \pm 0.563$ \\
60 & 45 & $35.05 \pm 0.002$ & $129.04 \pm 0.508$ \\
60 & 60 & $35.05 \pm 0.005$ & $129.61 \pm 0.060$ \\
70 & $36.51 \pm 0.010$ & $132.98 \pm 2.018$ \\
70 & 15 & $36.99 \pm 0.005$ & $139.11 \pm 1.168$ \\
70 & 30 & $39.84 \pm 0.006$ & $145.34 \pm 1.096$ \\
70 & 45 & $39.14 \pm 0.007$ & $144.27 \pm 0.065$ \\
80 & 60 & $33.04 \pm 0.004$ & $123.31 \pm 1.664$ \\
80 & 15 & $36.04 \pm 0.003$ & $127.77 \pm 1.141$ \\
80 & 30 & $39.87 \pm 0.114$ & $145.34 \pm 1.096$ \\
80 & 45 & $38.24 \pm 0.002$ & $139.61 \pm 0.548$ \\
\hline
\end{tabular}

Values are expressed as mean $\pm \mathrm{STD}$. 
$\begin{aligned} \text { FRAP }_{\mathrm{UAE}}= & -384.824+14.48 A+0.058 B-0.104 A^{2}+0.012 A B- \\ & 0.008 B^{2}\end{aligned}$

$R^{2}=90.16 \%, R^{2}(\operatorname{adj})=.88.52 \%, \mathrm{SEE}=1.10$,

where $A$ is extraction temperature $\left({ }^{\circ} \mathrm{C}\right)$ and $B$ is extraction time (minute).

Analysis of variance showed that the $p$ values of the models and effects were less than 0.05 , indicating that they were significant at the $95.0 \%$ confidence level (Table 5 and Fig. 1). From Figures 2 and 3 confirmed with previous results, extraction temperature and time strongly influenced anthocyanin content and antioxidant capacity of the extract. Under suitable conditions, the highest concentration in the extract could be observed. However, it should be considered that there are other affecting factors to avoid the loss of TAC and antioxidant activity.

Figure 4 shows the combination of desired functional maximization factor levels (TAC and FRAP maximization) on the indicated region. It also showed the combination of factors at which the optimal level is reached. The optimal values of TAC and FRAP obtained were $39.90 \mathrm{mg} / \mathrm{l}$ and $146.56 \mu \mathrm{MFeSO} 4 / 100 \mathrm{ml}$ when the butterfly pea flower was extracted at approximately $74^{\circ} \mathrm{C}$ for 56.88 minutes.

By UPLC/UV/MS analysis, five anthocyanin compounds, delphinidin-hex, cyanidin-hexose-deoxyHex, delphinidindeoxyhex-hex, cyanidin-hexose-2 deoxyHex, and delphinidinhexose-2 deoxyHex, were identified (Fig. 5).

Table 5. Analysis of variance of models.

\begin{tabular}{|c|c|c|c|c|c|c|c|c|c|c|}
\hline \multirow[b]{2}{*}{ Source } & \multicolumn{5}{|c|}{ Anthocyanin (mg/l) } & \multicolumn{5}{|c|}{$\operatorname{FRAP}\left(\mu \mathrm{MFeSO}_{4} / 100 \mathrm{ml}\right)$} \\
\hline & $\mathbf{S S}^{\mathbf{a}}$ & $\mathbf{D f}^{\mathrm{b}}$ & $\mathbf{M S}^{\mathbf{c}}$ & $F$-ratio & $p$ value & SS & Df & MS & $F$-ratio & $p$ value \\
\hline Model & 184.80 & 5 & 36.96 & 61.18 & 0.0000 & 2387.36 & 5 & 477.47 & 54.98 & 0.0000 \\
\hline Residual & 18.12 & 30 & 0.61 & & & 260.54 & 30 & 8.68 & & \\
\hline Total (Corr.) & 202.92 & 35 & & & & $2,647.91$ & 35 & & & \\
\hline
\end{tabular}

${ }^{a}$ Sum of square.

${ }^{b}$ Degree of freedom.

${ }^{\mathrm{c}}$ Mean square.

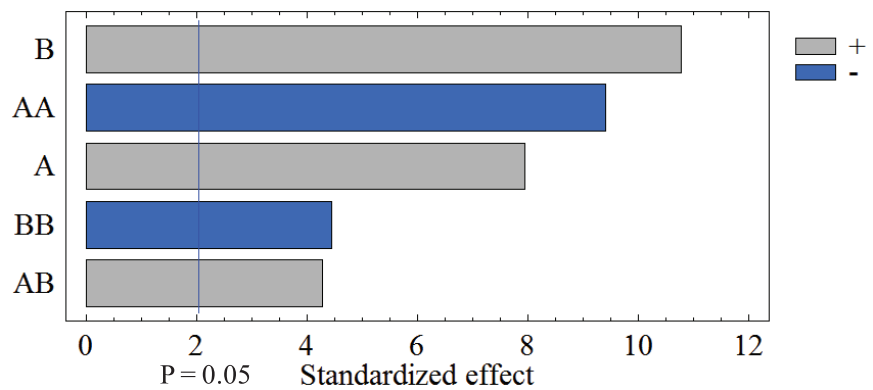

(a) TAC

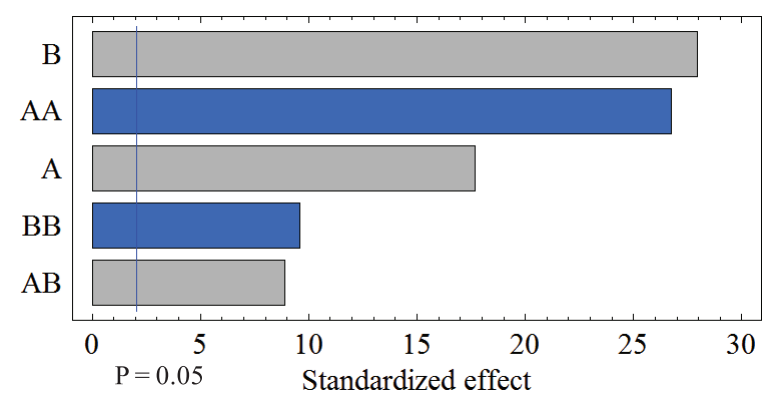

(b) FRAP

Figure 1. Standardized pareto chart for TAC (a) and FRAP (b) in extract.

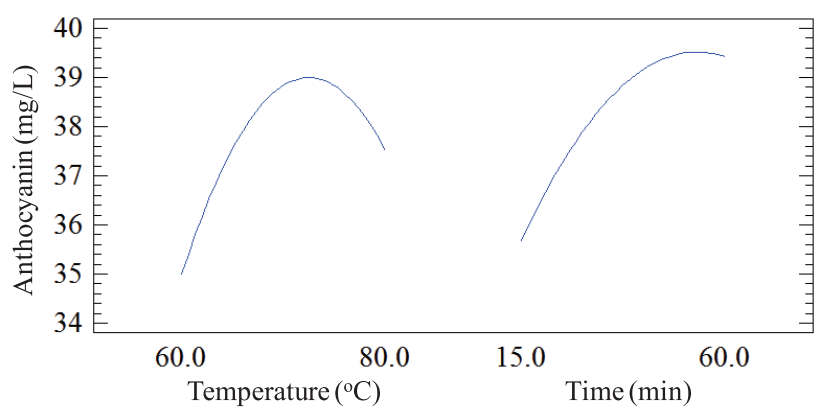

(a) TAC

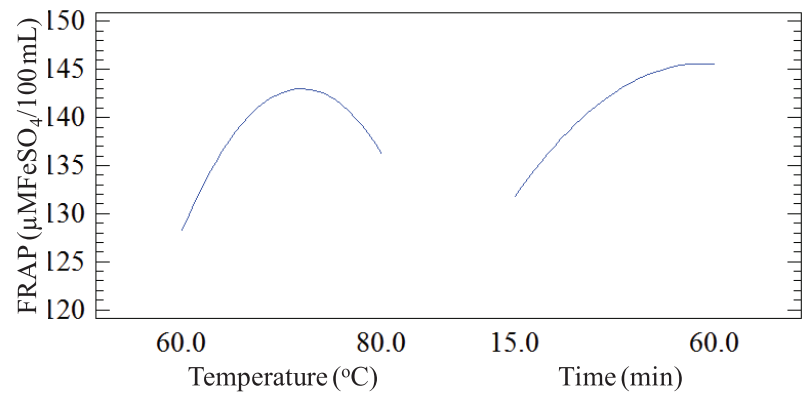

(b) FRAP

Figure 2. Main effects plot for TAC (a) and FRAP (b) in extract. 


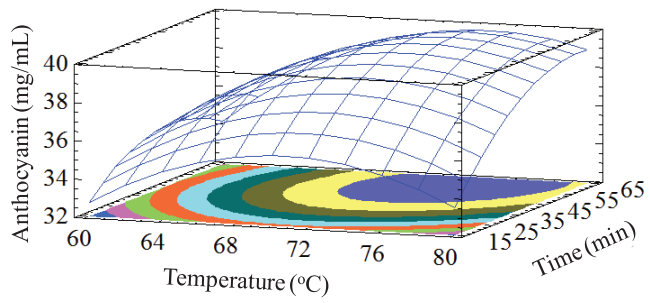

(a) TAC

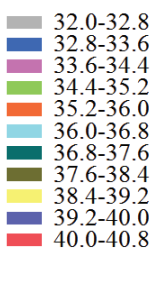

Figure 3. Estimated response surface plot for TAC (a) and FRAP (b) in extract.

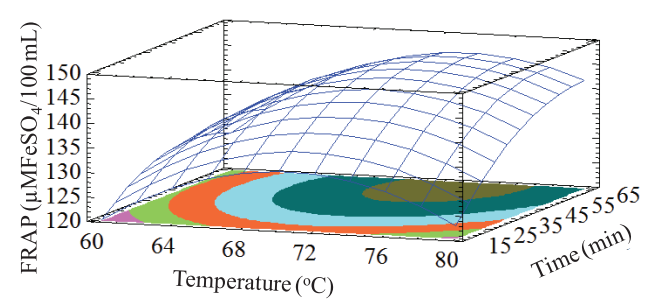

(b) FRAP

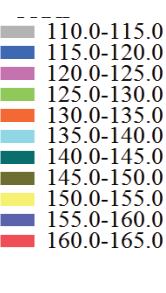

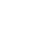

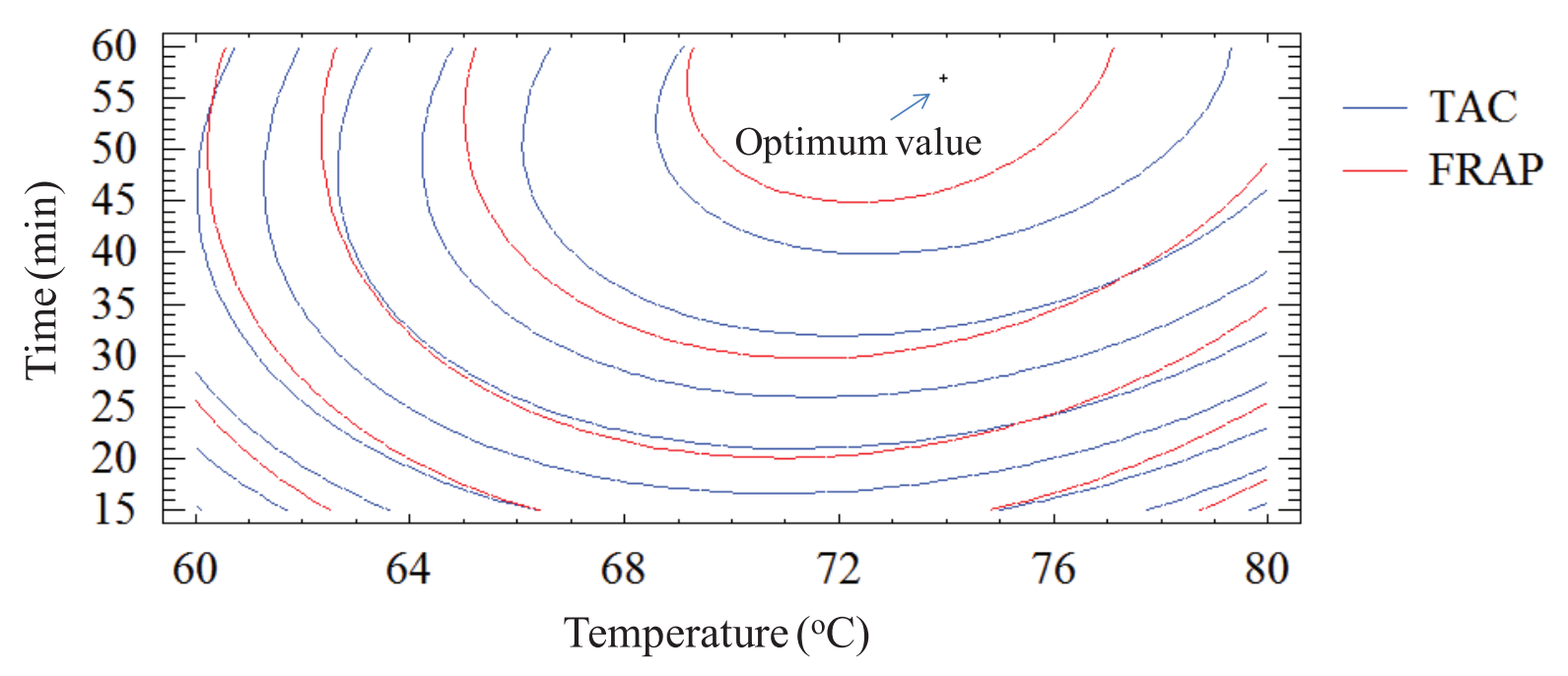

Figure 4. The overlay plot for TAC and FRAP in extract and optimum value.
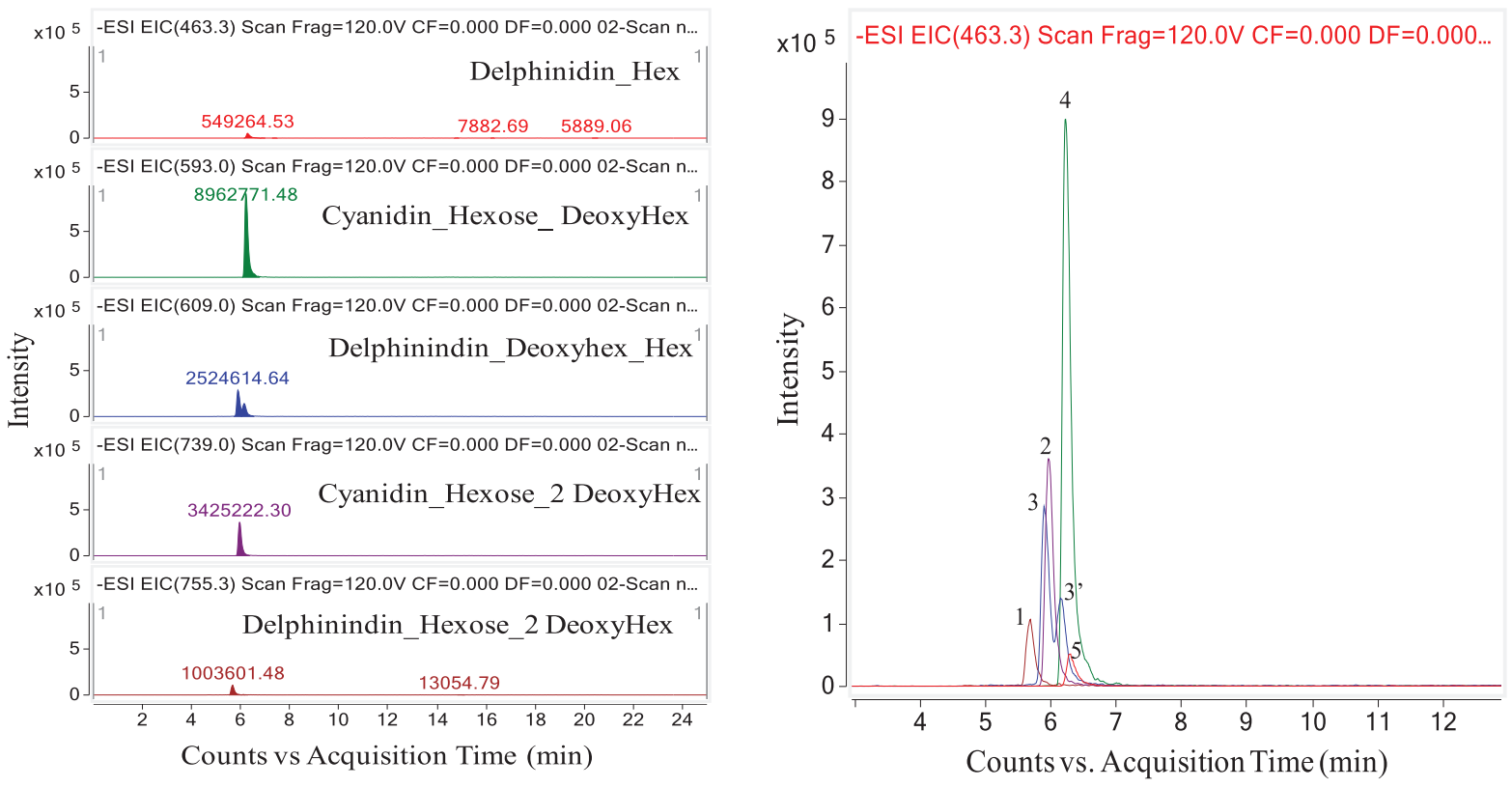

Figure 5. Anthocyanin compounds in butterfly pea flower by UPLC/UV/MS. 


\section{CONCLUSION}

Ultrasonic- and MAE processes can be successfully applied to extract bioactive compounds from butterfly pea flowers with high bioactivity. However, using the UAE technique has many advantages over other techniques. With this extraction method, the anthocyanin content and antioxidant capacity of the extract were obtained at $39.90 \mathrm{mg} / \mathrm{l}$ and $146.56 \mu \mathrm{MFeSO}_{4} / 100 \mathrm{ml}$, respectively. The obtained extract could be effectively used in processing traditional cakes and popular dishes in Vietnam instead of using synthetic colorants.

\section{AUTHOR CONTRIBUTIONS}

All authors made substantial contributions to conception and design, acquisition of data, or analysis and interpretation of data; took part in drafting the article or revising it critically for important intellectual content; agreed to submit to the current journal; gave final approval of the version to be published; and agree to be accountable for all aspects of the work. All the authors are eligible to be an author as per the international committee of medical journal editors (ICMJE) requirements/guidelines.

\section{FUNDING}

There is no funding to report.

\section{CONFLICTS OF INTEREST}

The authors report no financial or any other conflicts of interest in this work.

\section{ETHICAL APPROVALS}

This study does not involve experiments on animals or human subjects.

\section{PUBLISHER'S NOTE}

This journal remains neutral with regard to jurisdictional claims in published institutional affiliation.

\section{REFERENCES}

1. Mohamad MF, Nasir SNS, Sarmidi MR. Degradation kinetics and colour of anthocyanins in aqueous extracts of butterfly pea. Asian J Food Ag-Ind 2011;4(05):306-15.

2. Marpaung AM, Andarwulan N, Prangdimurti E. Optimization of anthocyanin pigment extraction from butterfly pea (Clitoria ternatea $\mathrm{L}$.) petal using response surface methodology. Acta Hortic 2013;1011:205-11; doi:10.17660/ActaHortic.2013.1011.24

3. Jaafar NF, Ramli ME, Salleh RM. Optimum extraction condition of Clitorea ternatea flower on antioxidant activities, total phenolic, total flavonoid and total anthocyanin contents. Trop Life Sci Res 2020;31(2):1-17; doi:10.21315/tlsr2020.31.2.1

4. Pandey KB, Rizvi SI. Plant polyphenols as dietary antioxidants in human health and disease. Oxid Med Cell Longev 2009;2(5): 270-8; doi:10.4161/oxim.2.5.9498

5. Abubakar AR, Haque M. Preparation of medicinal plants: basic extraction and fractionation procedures for experimental purposes. J Pharm Bioallied Sci 2020;12:1-10; doi:10.4103/jpbs.JPBS_175_19

6. Kataoka H. Microwave assisted extraction. In: Townshend A, Poole CF, Miró M, Worsfold P (eds.). Encyclopedia of analytical science. 3rd edition, Elsevier, Amsterdam, Netherlands, 2019.
7. Chemat F, Rombaut N, Anne-GaëlleS, Meullemiestre A, FabianoTixier A, Abert-Vian M. Ultrasound assisted extraction of food and natural products. Mechanisms, techniques, combinations, protocols and applications. A review. Ultrason Sonochem 2017;34:540-60; doi:10.1016/j.ultsonch.2016.06.035

8. Guisti MM, Wrolstad RE. Characterization and measurement of anthocyanins by UV-Visible spectroscopy. In: Wrolstad RE, editor. Current Protocols in Food Analytical Chemistry (F1.21-F1.2.13). John Wiley \& Sons, New York, NY, 2001; doi:10.1002/0471142913. faf0102s00. Available via https://currentprotocols.onlinelibrary.wiley. $\mathrm{com} /$ doi/10.1002/0471142913.faf0102s00

9. Adedapo AA, Jimoh FO, Afolayan AJ, Masika PJ. Antioxidant properties of the methanol extracts of the leaves and stems of Celtis africana. Rec Nat Prod 2009;3(1):23-31. Available via https://www. acgpubs.org/doc/201808051331252-RNP\%200808-43.pdf

10. Backes E, Pereira C, Barros L, Prieto MA, Genena AK, Barreiro MF, et al. Recovery of bioactive anthocyanin pigments from Ficus carica $\mathrm{L}$. peel by heat, microwave, and ultrasound based extraction techniques. Food Res Int 2018;113:197-209; doi:10.1016/j.foodres.2018.07.016

11. Piyapanrungrueang W, Chantrapornchai W, Haruthaithanasan V, Sukatta U, Aekatasanawan C. Comparison of anthocyanin extraction methods from high anthocyanin purple corn cob hybrid: KPSC 901, and quality of the extract powder. J Food Process Pres 2016;40(5):112533; doi:10.1111/jfpp.12693

12. Oancea S, Stoia M, Coman D. Effects of extraction conditions on bioactive anthocyanin content of Vaccinium corymbosum in the perspective of food applications. Procedia Eng 2012;42:489-95; doi:10.1016/j.proeng.2012.07.440

13. Shi J, Yu J, Pohorly J, Young JC. Optimization of the extraction of polyphenols from grape seed meal by aqueous ethanol solution. J Food Agric Environ 2003;1:42-7. Available via https://agris.fao.org/agrissearch/search.do?recordID=FI2016100307

14. Naczk M, Shahidi F. Extraction and analysis of phenolics in food. J Chromatogr A 2004;1054:95-111; doi:10.1016/S00219673(04)01409-8

15. Silva EM, Souza JNS, Rogez H, Rees JF Larondelle Y. Antioxidant activities and polyphenolic contents of fifteen selected plant species from the Amazonian region. Food Chem 2007; 101:1012-8; doi:10.1016/j.foodchem.2006.02.055

16. Hou Z, Qin P, Zhang Y, Cui S, Ren G. Identification of anthocyanins isolated from black rice (Oryza sativa L.) and their degradation kinetics. Food Res Int 2013;50(2):691-7; doi:10.1016/j.foodres.2011.07.037

17. Syafa'atullah AQ, Amira A, Hidayati S, Mahfud M. Anthocyanin from butterfly pea flowers (Clitoria ternatea) by ultrasonic-assisted extraction. In AIP Conference Proceedings. AIP Publishing LLC, Melville, NY, 2020, vol 2237(1), p 020069; doi:10.1063/5.0005289

18. Anthika B, Kusumocahyo SP, Sutanto, H. Ultrasonic approach in Clitoria ternatea (butterfly pea) extraction in water and extract sterilization by ultrafiltration for eye drop active ingredient. Procedia Chem 2015;16:237-44; doi:10.1016/j.proche.2015.12.046

19. Orsat V, Routray W. Microwave-assisted extraction of flavonoids. In Munoz MJG, Dominguez H (eds.). Water extraction of bioactive compounds. Elsevier, Amsterdam, Netherlands, pp 221-244, 2017; doi:10.1016/B978-0-12-809380-1.00008-5

20. Chan $\mathrm{CH}$, Lim JJ, Yusoff R, NgohGC. A generalized energybased kinetic model for microwave-assisted extraction of bioactive compounds from plants. Sep Purif Technol 2015;143:152-60; doi:10.1016/j.seppur.2015.01.041

21. Bonfigli M, Godoy E, Reinheimer MA, Scenna NJ. Comparison between conventional and ultrasound-assisted techniques for extraction of anthocyanins from grape pomace. Experimental results and mathematical modeling. J Food Eng 2017;207:56-72; doi:10.1016/j.jfoodeng.2017.03.011

22. Jain NN, Ohal CC, Shroff SK, Bhutada RH, Somani RS, Kasture VS, et al. Clitoria ternatea and the CNS. Pharmacol Biochem Behav 2003;75:529-36; doi:10.1016/S0091-3057(03)00130-8 
23. Armenta S, Garrigues S, De la Guardia M. Green analytical chemistry. Trend Anal Chem 2008;27:497-511; doi:10.1016/j.trac.2008.05.003

24. Chemat F, Rombaut N, Sicaire AG, Meullemiestre A, FabianoTixier AS, Abert-Vian M. Ultrasound assisted extraction of food and natural products. Mechanisms, techniques, combinations, protocols and applications. A review. Ultrason Sonochem 2017;34:540-60; doi:10.1016/j.ultsonch.2016.06.035

25. Thuy NM, Tuyen NTM, Cuong NP, Huyen LTN, Phuong NP, Nguyen LTT, et al. Identification and extraction method of quercetin from flesh and skin of shallot (Allium ascalonicum) cultivated in Soc
Trang Province, Vietnam. Food Res 2020;4(2):358-65; doi:10.26656/ fr.2017.4(2).306

How to cite this article:

Thuy NM, Ben TC, Minh VQ, Tai NV. Effect of extraction techniques on anthocyanin from butterfly pea flowers (Clitoria ternatea L.) cultivated in Vietnam. J Appl Biol Biotech 2021; 9(06):173-180. 